\title{
ACERCAMIENTO PRAGMÁTICO AL DIÁlOGO DE LAS COMEDIAS BÁRBARAS, DE VALLE-INCLÁN
}

\author{
Monique Martinez Thomas \\ Université de Toulouse-Le Mirail
}

En nuestro teatro occidental, el diálogo constituye la parte más importante del texto; es «tradicionalmente» la base del mensaje dramático.

La semiología teatral, en su labor de conceptualizar los ingredientes propios de la teatralidad -espacio, tiempo, doble enunciación-, se ha interesado recientemente por el diálogo, a la luz de la filosofía del lenguaje, la pragmática y las investigaciones sobre el intercambio dialogal.

Partiré, en este estudio, una vez más, de uno de los trabajos de Anne Ubersfeld, Lire le théâtre III, Le dialogue de théâtre, que publica en 1996 y donde condensa las mayores aportaciones de Austin, Searle, Goffman y C. Kebrat-Orecchioni ${ }^{1}$.

1 Anne UBERSFELD, Lire le théâtre III, Le dialogue de théâtre, Paris: Belin, 1998 (Collection Belin Lettres Sup). 
Así define la índole peculiar del diálogo teatral, que justifica plenamente el enfoque metodológico elegido:

1. El diálogo teatral reproduce la palabra humana, remite a relaciones de comunicación «reales», a un intercambio «verdadero».

2. Pero, a la vez, su funcionamiento es estético, la palabra tiene una función estética, es un elemento de una percepción estética.

3. El enunciado teatral es un acto de lenguaje destinado a un destinatario, el receptor directo del discurso, identificado, reconocible, y el receptor indirecto, indefinido, «escondido», el espectador. El juego de lo que se dice para el uno y para el otro es el núcleo del juego teatral. El espectador oye la palabra que se le dirige a través de la palabra reflejada por el personaje.

La crítica valle-inclanesca, desde la euforia de los años sesenta y la mítica revalorización del autor gallego, no ha dejado de interesarse por su impresionante obra hasta nuestros días. Después de los prolijos y numerosos ensayos sobre el esperpento ${ }^{2}$, el interés se centra ahora en obras menos estudiadas, aunque no menos fascinantes. Entre aquéllas, la trilogía de Las comedias bárbaras (Cara de Plata, Aguila de blasón y Romance de lobos) ${ }^{3}$ ha venido suscitando trabajos interesantes, a finales de la década de los $90^{4}$. Si los aspectos históricos, culturales, míticos o dramatúrgicos se han estudiado bastante, me parece que todavía queda por aclarar el funcionamiento de las réplicas, a la luz de las teorías sobre el intercambio dialogal. Quizás nos pueda ayudar a entender mejor la índole de esta escritura teatral, muy estudiada por lo que concierne a la parte didascálica. La originalidad y belleza del texto didascálico, desconcertante y deslumbrador, ha contribuido a una relativa ocultación del diálogo teatral, cuyo funcionamiento resulta, para los estudiosos, menos problemático.

Estudiar el diálogo en el teatro es volver a construir las condiciones de la comunicación, que constituyen las premisas necesarias para la interpretación 5 .

2 Véase el análisis del fenómeno de mitificación del esperpento en Monique MARTINEZ THOMAS, Los herederos de Valle-Inclán ¿Mito o realidad?, Murcia: Servicio de Publicaciones, 1997.

3 Utilizaré aquí las ediciones de las Comedias Bárbaras de Ricardo DOMENECH, en la colección Austral de Espase Calpe (1995/1996/1996).

4 Véanse las revistas Co*textes, Les Comedias Bárbaras de Valle-Inclán, n.․ 31 § 32, Montpellier: Editions du Centre d'Études et de Recherches Sociocritiques, 1996, (Textes réunis par Daniel Meyran) e Hispanística XX, Les comédies barbares, Dijon: Université de Bourgogne, 1996.

5 Aunque, por razones evidentes, dedique un capítulo especial a cada aspecto relevante del análisis pragmático del diálogo teatral, no dejaré de utilizar conjuntamente todas las herramientas proporcionadas por Anne Ubersfeld. De antemano me disculpo por la molestia que pueda causar ese procedimiento. 


\section{LOS CONDICIONANTES DEL INTERCAMBIO DIALOGAL}

Las teorías pragmáticas, a través de la linguística de la enunciación y la teoría de los actos de lenguaje, ha aclarado la noción de «contexto» en la interacción verbal, poniendo de relieve, entre otros parámetros, la importancia

- del marco espacio-temporal («setting»), cuya configuración física y función social son decisivos para el intercambio;

- del número e índole de los participantes, cuyas características individuales - biológicas y físicas, sociales, psicológicas - y relaciones mutuas - grado de conocimiento, vínculo social y afectivo - condicionan sus relaciones dialógicas ${ }^{6}$.

En el teatro estas nociones vienen definidas principalmente por el texto didascálico, que prevé los signos no verbales de la comunicación. En él se define, con más o menos precisión, el lugar escénico, el tiempo ficcional y se presenta o describe a los personajes, de manera objetiva o subjetiva, según las estrategias enunciativas del «didascalos» 7 .

\section{La índole de las distintas entidades}

El intercambio dialogal depende de quién habla, a quién y a veces delante de quién se desarrolla el intercambio dialogal. Las características semánticas de los personajes son unos de los condicionantes fundamentales del intercambio dialogal. Hay que definir los rasgos específicos de cada interlocutor (su identidad, su profesión, su supuesta personalidad moral y psicológica) para entender sus relaciones dialogales. Es evidente que el trabajo de composición del retrato del personaje es un constante vaivén entre los datos conocidos y por conocer, ya que el personaje es un «ser de papel», que se contruye a lo largo de la obra teatral. Se conoce al personaje a través de su discurso, de lo que dicen los otros personajes de él y a través de las didascalias.

En la escena sexta de la jornada segunda de Romance de lobos, no se puede entender el funcionamiento del polílogo entre chalanes y segundones si no sabemos quién es Oliveros. Nos lo dice claramente la extensa didasca-

\footnotetext{
6 Véase KerBRAT-ORECCHIONI, Catherine. Les interactions verbales, tome I, Paris: Armand Colin, pp. 75-86.

7 Para el estudio de las didascalias, véase Golopentia/MARTINEZ-ThOMAs, Voir les didascalies, Gap/Ophrys, 1994, de próxima publicación en España, por la editorial Asociación de Directores de Escena de España. Sobre la noción de contexto en el texto de teatro, remitimos al ensayo de Thierry GAllÈPE, Didascalies. Les mots de la mise en scène, Paris: L'Harmattan, 1997, pp. 31-40.
} 
lia que precede al intercambio: Oliveros, el hijo mayor de Ramiro de Bealo tiene «el noble y varonil tipo suevo de un hidalgo montañés». Pero sobre todo aclara su filiación ilegítima con Don Juan Manuel, cuando evoca el rasgo típico de la familia Montenegro («el corvar de la nariz soberbio»), «que recuerda la juventud putañera de Don Juan Manuel Montenegro» (p. 114). Oliveros es pues uno de los numerosos bastardos del caballero, que usó, otra vez, del derecho de pernada, ya que «Ramiro de Bealo ha conseguido por ello que el viejo linajudo le diese en parcería cuatro yuntas, y en aforo las tierras de Lantañón.» (p. 114):

LOS CHALANES. ¡Santos y buenos días!

LOS SEGUNDONES. ¡Santos y buenos!

RAMIRO DE BEALo. ¿El Señor Don Mauro camina para su casa de Bealo?

DON MAURo. Para allá se camina.

RAMIRO DE BEALO. ¿Tornan del entierro de la señora mi ama, que goce de Gloria?... ¡Dios les otorgue su santa conformidad!... ¿Por allá verían a la parienta? Cuando salimos para la feria, díjonos que tenía determinado acudir. ¡Por allá la verían! Nos hubiéramos cumplido como ella, de no hallarnos con un buey escordado, sin yunta para labrar la tierra... Si Dios nos mantiene con vida y salud, el domingo bajaremos a la villa para oír una misa y saludar al Señor Don Juan Manuel.

Don MAURo. Pues yo os digo que en la casa de mi padre hacéis vosotros la misma falta que los canes en la de Dios. Eso os digo.

DON GoNZALITO. Harto habréis ordeñado esa vaca, y no penséis que muerta mi madre...

OLIVEROS. Pues allá iremos, sin contar con su venia.

RAMIRO DE BEALO. ¡Calla, rapaz! No muevas pleitos.

OLIVEROS. Hablo aquello que bien me parece, mi padre.

DON ROSENDo. iLo malo será que te arranquen la lengua!

OLNVROS. La defienden los dientes.

RAMIRO DE BEALO. Ten miramiento, rapaz.

DON ROSENDO. Defensa de mujer.

OLIVEROS. Y de lobo.

DON MAURo. ;No te los haga yo dejar clavados en la tierra!

OLIVEROS. ;Mucho hablar es!...

DON GONZALO. Si los quieres bien, no los saques al aire.

OLIVEROS. ¡Mírenlos!

OLIVEROS muestra los dientes albos, jóvenes, fuertes, con un gesto lleno de violencia, que recoge los labios y los estremece con sanguinaria y primitiva fuerza.

DON MAURO. iDientes de hambre, no asustan!

OLNEROS. ¡Hambre de morder!

DON GONZALTTO. Un mendrugo.

DON ROSENDO. ¡Cadelo sarnoso!

OLIVEROS. De su sangre me vendrá la sarna.

RAMIRO DE BEALO. Rapaz, ten miramiento, que son más que tú.

OLVEROS. A ustede, tócale callar mi padre.

RAMIRo. Que ellos son caballeros, rapaz.

OLIVERos. De la nobleza que vengan, vengo yo.

DON RoSENDo. Por detrás de la Iglesia no hay nobleza, sino hijos de puta.

DON MAURO. Tú siempre serás el hijo de un cuerno de Ramiro de Bealo.

OLIVEROS. Ni de puta ni de cabrón soy nacido, ni nunca dos veces me lo dijeron (p. 114-116). 
Empieza el polílogo de manera anodina, con fórmulas rituales de saludo, correspondidas entre ambos campos. Se inicia luego el intercambio con dos preguntas de Ramiro de Bealo a Don Mauro, el primogénito, que como tal se convierte en el alocutorio privilegiado del chalán. Entre el grupo de los chalanes, es lógico que sea Ramiro de Bealo quien toma la palabra. Tiene una posición específica respecto a Don Juan Manuel, por los privilegios obtenidos por el derecho de pernada. Por eso se siente autorizado a una larga réplica, en la que alude a la muerte de Doña María, dándoles el pésame, evoca la presencia de su mujer en el entierro y anuncia su intención de ir a saludar a Don Juan Manuel el domingo. Pero de repente se produce una ruptura en el intercambio. Desarrollado de manera aparentemente feliz, se corta explosivamente con la respuesta tajante y violenta de Don Mauro. La réplica, subrayada por la repetición de "os digo», tiene la fuerza ilocutiva de una sentencia jurídica. Se trata aquí de la afirmación de un nuevo poder a través de la palabra, como lo indica el adverbio «pues». El cambio de situación ha modificado las relaciones entre los hablantes, ya que, muerta la madre, son los hijos quienes van a mandar. Don Mauro rompe también con las leyes básicas de la conversación, con el insulto «canes», que provoca un cambio en el perfil dialógico del intercambio. Ramiro desaparece como (inter)locutor principal, tomando Oliveros la palabra. Se crearán entonces dos espacios dialógicos: el principal en el que se enfrentarán los hijos legítimos y el hijo ilegítimo del Caballero y otro secundario, en el que Ramiro intentará tranquilizar a su hijo. Éste se da cuenta de que efectivamente la regla del juego ha cambiado y que no puede tener ya ningún papel en el intercambio dialogal. Este segundo espacio dialógico funcionará como un contrapunto del primero hasta el final, con un encadenamiento de órdenes y de consejos por parte del padre, rechazados por el hijo, cuyas réplicas están irónicamente finalizadas por «mi padre». La emergencia de Oliveros como locutor está sujeta al presupuesto factual expuesto anteriormente: se atreve a oponerse porque es un bastardo y, con esta actitud dialógica, reivindica su filiación, sus derechos, el mismo poder que los hijos legítimos. Su afirmación, tan firme como la negación de Don Mauro, es el inicio de un duelo verbal: lo que está en juego es más el reconocimiento de su filiación que el de seguir gozando de los privilegios. Alude implícitamente a su padre, autorretratándose como un «lobo», lo mismo que los demás hijos. Cabe recordar la escena en la que el Caballero se enfrenta con su hijo Pedrito (II, 2): rra!

EL CABALLERo. A hijo tan bandido se le abre la cabeza. ¡Se le mata! ¡Se le entie-

DON PEDRTTO. ¡No me encienda la sangre, que si me vuelvo lobo, lo como!

EL CABALLERO. Apéate del caballo, y verás quién tiene más fieros dientes.

DON PEDRTOO. ¡No me tiente, señor!

EL CABALLERo. ¡Apéate, para que sepas quién es el lobo! (p. 90). 
Volvemos a encontrar en el discurso del hijo bastardo el mismo léxico (dientes, lobos). A partir del significante metafórico «mostrar los dientes», se va a encadenar una serie de réplicas violentas, en las que cada locutor se apodera de la metáfora para agredir o insultar a Oliveros. Don Mauro lo amenaza: « $i$ No te los haga yo dejar clavados en la tierra!» y Don Rosendo alude a su presunción: «Si los quieres bien, no los saques al aire». La metáfora se continúa a través de una acción no verbal, cobrando realidad escénica, cuando Oliveros muestra los dientes, como si fuera un lobo de verdad. Signos visuales que desencadenan otro insulto, con una construcción metafórica distinta, por parte de Don Mauro, «Dientes de hambre». Con este genitivo remite a la condición social pobre, de la familia de Oliveros, insulto frente al que reacciona el agredido otra vez con el mismo recurso «hambre de morder», que vuelve a afirmar su violencia primitiva de lobo, como toda la familia Montenegro. El significado implícito de la metáfora se aclara luego explícitamente: corre en ellos la misma sangre azul, el mismo origen aristocrático. «De su sangre me vendrá la sarna», afirma Oliveros a los segundones, «de la nobleza que vengan, vengo yo», frase que se dirige en realidad a los hijos legítimos y que desencadena los últimos insultos y el combate final.

Resulta imposible para Oliveros aceptar las relaciones de poder, la jerarquía social, el no reconocimiento, el insulto, pero el fracaso de esta tentativa de afirmación de sí mismo era previsible. Sólo aparece una vez en la trilogía, en esta escena y no tiene ningún papel en el esquema actancial. No se trata para Valle-Inclán de cuestionar la legitimidad del antiguo sistema feudal y arcaico, sino de pintar la barbarie de un mundo primario y violento.

Entre los condicionantes previos del intercambio dialogal, la configuración del espacio teatral (en sus tres dimensiones - escenográfico, escénico y dramático-) y la referencia temporal desempeñan también un papel fundamental.

\section{La situación de comunicación: las circunstancias espacio-temporales}

Un enunciado teatral no significa nada si no se toman en cuenta las condiciones concretas de enunciación. El espacio ficcional se suele fijar en las zonas didascálicas intermedias, cuando se abre una nueva unidad, cada vez que se cambia de espacio escénico.

En Las comedias bárbaras, los numerosos y variados espacios escénicos 8 remiten todos a un mismo espacio geográfico: Galicia, en un contexto histó-

8 Véase Monique Martinez Thomas, «El juego del didascalos. Las didascalias anti-funcionales de Las comedias bárbaras de Valle-Inclán», Las Comedias Bárbaras, Co*textes, $n .{ }^{\circ} 31$ § 32, Montpellier, 1996, pp. 67-92. 
rico preciso. Por ser aspectos muy desarrollados ${ }^{9}$, no me detendré en la significación (ideológica y mítica) de estos referentes. Lo que sí me interesa apreciar aquí son aquellos espacios escénicos que no sólo forman parte del contexto del enunciado, sino que alteran su significación.

Se dan unos de estos casos en la famosa escena cuarta de la última jornada de Romance de lobos, la escena de la cueva:

Una costa brava ante un mar verdoso y temeroso. Lomas de arena, con pinares desmedrados en lo alto, y en la bajada un charcal salobre, donde blanquean los huesos de una vaca. Larga bandada de cuervos revolotea sobre aquella carroña, bajo un cielo gris de amanecer. En el fondo de una caverna socavada por el mar, el viejo linajudo espera la muerte como un viejo león. Ante sus ojos nublados se ve aparecer la sombra de FUSO NEGRO.

FUSO NEGRO. ;TOu! ¡TOU! ; Tou!... Ya somos dos.

EL CABALLERO. ¡Tampoco aquí podré estar solo para morir en paz!...

FUSO NEGRo. El señor Mayorazgo tiene sus palacios y su cama con dosel... Aquí haránsele llagas las costas... Para el cuerpo de los señores es muy duro el cocho de Fuso Negro.

EL CABALLERO. ¿Duermes en esta cueva?

FUSO NEGRO. Unas veces duermo y otras veces velo.

EL CABALLERo. 'Yo te pido que me dejes morir aquí!

FUSO NEGRo. ¿Quiere hacerse ermitaño el Señor Mayorazgo? Iríase el loco a reinar en sus palacios. Tendrá su manto de una sábana blanca y su corona ribeteada de papel. Tendrá su mesa con pan y trigo y cuatro odres haciendo una cruz. El uno, de vino de Ribeiro; el otro, de vino de la Ramallosa; el otro, de vino blanco Alvariño, y el otro, del buen vino que beben los abades en la misa, y si parida, el ama en la cama. ;Iráse el loco a los palacios del Señor Mayorazgo!

EL CABALLERO. Ya no tengo palacios. Todo lo he repartido entre mis hijos para que no acabasen en la horca y fuesen deshonra de mi linaje. ;Todo lo di!

FUSO NEGRO. iTou! iTou! i Tou!... Ya somos hermanos.

EL CABALLERO. Un ángel y un demonio me están abriendo la sepultura, a la luz de un cirio. El ángel cava, el demonio cava... Uno a la cabecera, otro a los pies.

FUSO NEGRO. El ángel cava, el demonio cava... iBien que los veo! El demonio agora enciende un cigarro con un tizón que saca del rabo.

EL CABALLERo. ¿Tú los ves, Fuso Negro?

FUSO NEGRO. ¡Sí que los veo!

EL CABALLERO. ¿Estás seguro?

FUSO NEGRO. ¡Sí que los veo!

EL CABALLERO. Yo dudaba que fuese delirio de mis sentidos... Apenas distingo tu sombra en esta cueva. He venido aqui para morir... Fui toda mi vida un lobo rabioso, y como lobo rabioso quiero perecer de hambre en esta cueva... Hermano Fuso negro, me cortarás la cabeza y se la llevarás a mis hijos. Verás cómo te visten de seda esos monstruos nacidos de mi sangre.

FUSO NEGRO. ¿Cuántos son?

EL CABALLERO. CinCo.

FUSO NEGRO. ¡Cinco cirios, cinco rabos, cinco demonios coronados!

FUSO NEGRO. ¡Demonios son!

FUSO NEGRo. Hijos del Demonio mayor, que cinco veces estuvo en la cama con aquélla que ya dejó el mundo (p. 135-136). 1985.

9 Véase Lourdes Ramos-KuETHE, Valle-Inclán. Las comedias bárbaras, Madrid: Pliegos, 
¿Qué significa el diálogo de Don Juan Manuel con Fuso Negro dentro de la cueva? ¿Qué dice El Caballero dentro de la fosa? Pues dice que va a morir. Lo mismo que dijo a los mendigos en la escena anterior: «ya os dije que voy a morir» (p. 134). Tres veces delante de Fuso Negro se lamenta con no poder «morir en paz», le pide le deje «morir en paz», le aclara que ha venido aquí «para morir». La didascalia también lo apunta explícitamente: «el viejo linajudo espera la muerte como un viejo león». La cueva se da entonces como lugar de la muerte, tumba del caballero, última morada en las entrañas de la tierra. En realidad, le será imposible morir en la caverna:

- Porque simboliza el renacimiento, el regressus ad uterum. Si se muere, es muerte también simbólica para volver a nacer. La cueva es el lugar de regeneración al que conducen las pruebas del laberinto. Efectivamente, el caballero no va a morir allí, en esta matriz va a recoger nuevas fuerzas para una nueva misión: la de oponerse a sus hijos.

- Porque la cueva es una etapa en el itinerario de iniciación del Caballero. Simboliza el momento de exploración del yo primitivo, soterrado en el inconsciente. El antro, cavidad sombría, región subterránea, es un abismo terrible en el que surgen monstruos. Monstruo del delirio del caballero que atormentado ve cómo un ángel y un demonio están abriendo su sepultura. Estas dos entidades antagónicas que luchan para apropiarse de su muerte, de su alma, simbolizan el momento intermedio en el que todavía está el Caballero. Oscila entre el Bien y el Mal, porque su itinerario de redención no se ha llevado a cabo. La cueva simboliza así el purgatorio en el que la luz de la verdad se va transluciendo. La temática de la luz (con la repetición del verbo "ver») dentro de la evidente oscuridad de la cueva («apenas distingo tu sombra en esta cueva», le dice El Caballero a Fuso Negro), la precisión didascálica de los «ojos nublados» insiste en la visión simbólica que tiene el Caballero de su propia vida y de su sentimiento de culpabilidad. También monstruo de la cueva lo es Fuso Negro que viene a atormentar al caballero, removiendo los recuerdos de su pasado -el esplendor de antaño, la decadencia de hoy, la paternidad diabólica que engendra monstruos-. El monstruo Fuso Negro en la cueva del inconsciente le ayuda a explicar y a aceptar la filiación demoniaca: «Hijos del Demonio mayor, que cinco veces estuvo en la cama con aquélla que ya dejó el mundo». Tiene una función de revelador de su pasado.

- La cueva también remite al mito de Platón. Desde la oscuridad de la cueva se puede vislumbrar la luz que alumbra fuera. La cueva de Platón es la imagen del mundo de las apariencias, los hombres encadenados no pueden ver la luz de la verdad que está a sus espaldas, fuera de la cueva, pero sí tie- 
nen que dejarse guiar por el esplandor para encontrar el Bien y la Verdad. Las sombras que se reflejan en la cueva son un pálido reflejo del mundo de las ideas. Así se presenta Fuso Negro, como una sombra que se dibuja en la boca de la cueva, oscurecida también por la pálida luz del amanecer, al principio de la escena y luego por una «cortina cenicienta» de lluvia (p. 139). Podemos relacionar la función de revelador de Fuso Negro, que será la voz del secreto y de la verdad, con las sombras de la cueva de Platón. Del mismo modo, otras sombras asomarán, más tarde, en la boca de la cueva, revelando la ruptura del contrato social:

La cortina cenicienta de la lluvia ondula en el claro de luz que recorta la boca de la cueva. Algunas sombras llegan a cobijarse y se agrupan en el umbral, alentando afanosas de la carrera. Aquellas figuras que huyen del nublado se destacan por oscuro sobre el fondo del mar tendido de espuma. Son cuatro niños descalzos, con los pelos crespos, y una mujer de luto (...)

LA MUJER. (...) Esta mañana, rayando el día, fui a la casa grande por tener un socorro para este camino tan largo. iEcháronme los canes!... iMalditos sean todos los ricos! (...) ;Y tenían dicho que darían socorro a las viudas y a los huérfanos! ¡El Mayorazgo huyóse para no cumplirnos la manda! ¡Cinco lobos dejó alrededor de su silla vacía! ¡Ay, Montenegro, negro de corazón! „Por tu imperio se hicieron aquellos pobres a la mar, en una noche tan fiera! ;Cuando seáis mozos, reclamarle cuentas, mis hijos, que él os dejó sin padre! ¡Mal can le arranque el corazón, y lo lleve por este arenal! ;Mal cuervo le coma los ojos! ¡Malas ortigas le broten en el pecho! ;Mal avispero le nazca en la lengua!

EL CABALLERO. ¡Calla, mujer, que tus maldiciones ya se cumplen!

El Caballero se incorpora en el lecho de las algas, y la viuda y los cuatro niños tiemblan al reconocerle. En la oscuridad de la cueva apenas se distingue la sombra del viejo linajudo, y su voz tiene una resonancia oscura de caos y tinieblas como si saliese de la oquedad del roquedo (p. 140).

De este relato vendrá la toma de conciencia del Caballero, su nueva energía simbolizada por el «levantarse» de su lecho. Con este movimiento da fin a la etapa de introspección, de la que resurge con una nueva misión. Ha sacado las fuerzas telúricas de la cueva para emprender su nuevo camino definitivo hacia su redención.

Hemos podido comprobar que hablar en una cueva puede condicionar el enunciado del diálogo:

- no se puede decir que se está esperando la muerte porque la cueva es un lugar de renacimiento, de muerte sí, pero simbólica, para otra vida nueva,

- no se puede decir que se ven monstruos porque son delirios del inconsciente, que la cueva simboliza,

- no se puede ocultar la verdad en una cueva porque es el lugar donde se aprende la verdad, donde se establece la luz sobre las cosas. 
El análisis de los ingredientes del contexto dialogal nos lleva a una primera conclusión: la predeterminación del diálogo en Las comedias, a través de unas didascalias extensas y pormenorizadas, las características semánticas del contexto (fuerte referencialidad geográfica e histórica tanto para los personajes como para el espacio) abogan por una concepción «realista» del intercambio dialogal. No se trata, en estas obras, de romper con un referente verosímil para inventar un significante autónomo, que se autoengendra y crea una percepción ante todo poética ${ }^{10}$. Los enunciados están condicionados por elementos que el espectador puede captar y entender con relativa facilidad, con más o menos agudeza, según sus propios conocimientos culturales, históricos y míticos. De la misma forma veremos, en el apartado siguiente, cómo el discurso de los personajes obedece a la ley de «verosimilitud», reproduciendo los esquemas básicos de «la conversación normal», con todos los matices del diálogo ordinario.

\section{EL DIÁLOGO TEATRAL}

Desde las importantes investigaciones de la pragmática, sabemos que estudiar el diálogo teatral, como cualquier intercambio lingüístico, rebasa el mero análisis de la organización semántico-sintáctica de los signos. Si bien es verdad que el lenguaje siempre «dice algo», comunica una información, la significación del enunciado queda supeditada no sólo a los elementos contextuales «fijos», que acabamos de estudiar, sino también a otros «dinámicos», que están implicados en y durante el intercambio dialogal: la estrategia explícita o implícita de los actos de lenguaje, los condicionantes dialógicos previos (la historia conversacional y las leyes del discurso), el contenido implícito (presupuesto y sobreententido).

\section{La palabra-acto}

No cabe detenernos, en el espacio reducido de este artículo, en la teoría de los actos de lenguaje (o actos de habla), que, iniciada por Austín, ha representado un cambio copernicano para muchos campos de investigación. Sabido es que, desde las famosas conferencias del filósofo inglés, recopiladas por sus estudiantes en How to do things with words, que la palabra es

10 Para el análisis del funcionamiento de la escritura poética en el teatro, véanse mis dos artículos «La dramaturgie possible du théâtre impossible de Lorca: Así que pasen cinco años», en Le théâtre impossible de García Lorca, Paris, Le temps,1998, pp. 65-80 y «Notas de cocina de Rodrigo García: une lutte pour le pouvoir», en Théatre et Pouvoir, Perpignan: CRILAUP/CERTM, 1999 (sous presse). 
siempre un acto, que tiene un valor «performativo». Puede modificar la situación del interlocutor, modificar su sistema de creencias y/o su comportamiento, las relaciones entre los hablantes ${ }^{11}$.

Hace ya muchos años que la crítica teatral ha venido definiendo el lenguaje teatral por su valor performativo, desarrollándose la intriga a través de las relaciones de fuerza, de amistad, de amor que intercambian los personajes:

El discurso teatral se distingue, en efecto, del discurso literario "cotidiano" por su fuerza performativa, por su capacidad de cumplir simbólicamente una acción. Por una convención implícita, en el teatro, «decir es hacer» 12.

Veamos un ejemplo en Aguila de blasón, en la escena tercera de la tercera jornada. Mientras Doña María está intentando convencer al Caballero que reparta sus bienes entre sus hijos (III, 2), cuatro hermanos Montenegro están esperando la intercesión de la madre, haciendo tiempo:

Un atrio. En el fondo la Colegiata. Anochece. Al abrigo de la tapia se pasean DON ROSENDO, DON GONZALITO, DON MAURO y DON FARRUQUIÑO. Los cuatro son hijos del MAYORAZGo. Don FARRUQuiNo lleva manteo y tricornio, clásica vestimenta que aún conservan los seminaristas en Viana del Prior.

DON GONZALTTO. ;Tengo ansiedad por saber!...

DON MAURO. Yo, ninguna.

DON GONZALTTO. ¿Conseguirá mi madre convencer al viejo?

DON MAURO. No lo espero.

DON FARRUQUIÑO. Grande es el poder de la elocuencia, hermanos míos. Doña María sacará el Cristo.

DON MAURO. No creo en los milagros. Tengo por seguro que nos quedaremos como estamos.

DON GONZALTTO. Si lo piensas, lo callas.

DON MAURO. Sería preciso que alguien me pusiese la mano en la boca, y aún no ha nacido.

Don GonZALITo. La mano no, pero el puño...

DON MAURO. Ni la mano, ni el puño, ni el aire, yo digo aquello que mejor me parece, y quien no guste de oírlo se camina a otra parte.

DON ROSENDO. Tengamos paz.

DON FARRUQUiÑo. Paz y concordia entre los príncipes cristianos (p. 107-108).

11 Utilizo aquí la traducción francesa Quand dire, c'est faire, Paris: Seuil, 1991 (Points Essais), así como los libros de Searle: Les actes de langage, Paris: Hermann, 1972 y Sens et expression. Études de théorie des actes de langage, Paris: Minuit, 1982. Remito también al lector interesado por la teoría pragmática a los libros publicados recientemente en España: María Victoria Escandell VIDAl, Introducción a la pragmática, Barcelona/Madrid: Anthropos/UNED, 1993; Julio Calvo PÉREZ, Introducción a la pragmática del español, Madrid: Cátedra, 1994; Catalina FUENTES RODRíGUEZ, Introducción teórica a la Pragmática Lingüística, Sevilla: Facultad de Filología de Sevilla.

12 J. L. Austin, citado por Patrice Pavis, op. cit., p. 125. 
Analicemos el funcionamiento de este inicio de intercambio dialogal, que no tiene otra función que dibujar relaciones de fuerza entre los hermanos. Con su primera réplica, Gonzalito hace un acto de confesión, que tiene también una función informativa: está esperando el resultado de la entrevista de su madre con el caballero, suspense que el espectador no va a compartir (conoce la negativa de Don Juan Manuel). Pero también revela (a través de la exclamación) su estado anímico. Por este acto de confesión se dice en una posición de inferioridad, ya que no decide él las cosas, está supeditado a la decisión paterna, aclara su espera angustiada, revelando su debilidad, cosa que Don Mauro no va a aguantar. Con la brevedad de la réplica «yo nunca», éste se afirma independiente de los sucesos que tanto afectan a su hermano, insistiendo en su diferencia. Rompe también con la apertura hacia la comunicación que constituía la exclamación de Don Gonzalito. Don Mauro no quiere apiadarse de él, unirse con sus ansias. Niega pues la relación afectiva implícita en la confesión, rebaja en cierta forma a su hermano. El mismo esquema sigue con la réplica siguiente en la que Gonzalito vuelve a expresar su impotencia, con una interrogación acerca de la intervención de Doña María, aclarando su finalidad: "convencer al viejo». De la misma forma tajante, Don Mauro niega lo que él considera como flaqueza: la espera. Don Mauro se afirma como autosuficiente. Interviene Don Farruquiño en la riña de los dos hermanos (reunidos aquí como alocutorios) con una réplica humorística, acto que alivia la tensión que se está creando entre Gonzalito y Mauro. Pero también conecta, a través de la alusión al Cristo, con la impotencia de los hermanos, supeditados no sólo a la intervención de la madre sino a la de una entidad superior, Dios; lo que subraya todavía más su falta de control de la situación. Implícito que no escapa al orgullo de Mauro, que con una tercera fórmula negativa, niega las esperanzas de sus hermanos. Hace un acto de violencia verbal, rechazando la posibilidad del cambio que anhelan los demás. Violencia que no escapa a Gonzalo, que reacciona con otro acto de agresión, ordenándole que se calle. A partir de ahí, el encadenamiento de réplicas va a ser cada vez más tenso entre los dos hermanos. Mauro no soportará la privación de palabra y su réplica es acto de orgullo y de provocación: «Sería preciso que alguien me pusiese la mano en la boca, y aún no ha nacido», lo que acarrea la amenaza de enfrentamiento físico «puño», por parte de Gonzalito. Pero Don Mauro, con una réplica larga, se impone. Reinvidica su palabra como derecho intocable. Su discurso es acto de afirmación de sí y marginación del otro, acto de exclusión. Frente a esta violencia, los otros dos hermanos siguientes interceden en el intercambio. Intentan, con palabras apaciguadoras, romper la tensión creada entre los hermanos, con el contrapunto siempre irónico de Don Farruquiño. Sus intervenciones permiten cortar de raíz el diálogo, instalándose el silencio durante algunos minutos. Este principio de intercambio, en el que predominan actos de violencia 
verbal, es simbólico de lo que es la familia Montenegro: una familia de lobos hambrientos y crueles que se devorarán entre sí.

Según J. L. Austin, el acto de habla contiene tres fases:

- La expresión de un contenido semántico a través de elementos fónicos, gramaticales y semánticos (nivel locutivo).

- Un poder afectivo en el receptor (sentimiento de miedo, de esperanza, de satisfacción) (nivel perlocutivo).

- Una fuerza que instituye cierto tipo de relación convencional con el otro (un contrato entre el yo y el otro) (nivel ilocutivo).

Unos de los fragmentos más interesantes para acercarnos al funcionamiento de los actos de lenguaje es, indudablemente, el incipit de Águila de blasón:

Fray Jerónimo Argensola, de la regla franciscana, lanza anatemas desde el púlpito, y en la penumbra de la iglesia la voz resuena pavorosa y terrible. Es un jayán fuerte y bermejo, con grandes barbas retintas. El altar mayor brilla entre luces, y el viejo sacristán, con sotana y roquete, pasa y repasa espabilando las velas (...) Fray Jerónimo, después de la novena, predica la plática. Es la novena de Nuestra Señora de la Piedad.

FRAY JERÓNIMO. iEl pecado vive con nosotros, y no pensáis en que la muerte puede sorprendernos! Todas las noches vuestra carne se enciende con el fuego de la impureza, y el cortejo que recibís en vuestro lecho, que cobijáis en las finas holandas, que adormecéis en vuestros brazos, es la sierpe del pecado que toma formas tentadoras. ¡Todas las noches muerde vuestra boca la boca pestilente del enemigo!

Se oyen algunos suspiros, y una devota se desmaya. La rodean otras devotas, y en la oscuridad albean los pañolitos blancos, que esparcen un olor de estoraque al abanicar el rostro de la desmayada. Varias voces susurran en la sombra.

UNA VIEJA. ¿Quién es?

UNA MOZA. No sé, abuela.

UN MONAGO. Es la amiga del Mayorazgo...

OTRA VIEJA. ¡Para qué vendrá la mal casada a la iglesia!

UNA VOZ EN LA SOMBRA. Querrá arrepentirse, tía Juliana (p. 52-53).

La plática de Fray Jerónimo es un acto de denuncia del estado pecaminoso en el que viven los hombres (valor locutivo). Se refiere al pecado de lujuria, al amor carnal como acto endemoniado y todo contribuye a una escenificación de su discurso: el púlpito que funciona como lugar escénico, la luz (la penumbra de la iglesia) que dramatiza la escena, el conjunto semiótico del actor, Fray Jerónimo, «jayán fuerte y bermejo», con grandes barbas retintas y voz teatral, que «resuena pavorosa y terrible». Hay un ensanchamiento épico de la escena, que cobra otra dimensión más que la de un sencillo ritual religioso. La primera exclamación efectista, sensacionalista, se construye con un ritmo binario, con fuerte oposición semántica marcada por la «y»: apunta a la 
paradoja entre el estado pecaminoso cotidiano y la ausencia de arrepentimiento para morir como cristianos (reproche implícito en la fórmula generalizadora «no pensáis que la muerte puede sorprendernos»). La larga frase siguiente no hace más que desarrollar el corto sintagma inicial: «el pecado vive con vosotros». Este pecado de lujuria cobra aquí, retóricamente, una dimensión desmesurada con la puesta de relieve del substantivo «cortejo», sujeto de las tres oraciones relativas que repiten la misma información: el amor carnal. Con la segunda repetición del complemento temporal antepuesto al verbo, en posición anafórica, «Todas las noches», con la exclamación, dramatiza descomunalmente el pecado carnal, siendo los amantes encarnaciones del diablo.

El valor ilocutivo más evidente, «primario» ${ }^{13}$, del discurso de Fray Jerónimo, es decir, la intencionalidad del locutor al pintar el pecado carnal es inducir un cambio. Lo que quiere decir el fraile es lo siguiente: «tenéis que arrepentiros, dejar de ser lujuriosos para morir como cristianos y no ir al infierno». Pero ningún término se refiere al arrepentimiento, al perdón, al cielo, a la rendención, toda idea de piedad queda aniquilada. Fray Jerónimo evoca una situación que parece irremediable, definitiva, como lo subrayará más tarde, diciendo: «Pero como vuestra alma no se edifica, sigue prisionera en las cárceles oscuras del pecado» (p. 52). Más que una denuncia abierta hacia un cambio de actitud, hay cierta complacencia por parte del fraile en evocar la realidad del pecado, que además pinta acertadamente «fuego» - lecho, cobijar, sierpe, muerde, boca-, léxico realista o simbólico que alude precisamente al acto sexual. El segundo valor locutivo, «derivado», sería pues «quedaros en la lujuria porque a mí me place hablar de ello», porque vuelve a recrear la realidad del amor a través de las palabras (lo mismo que luego describirá, con una minuciosidad macabra, la muerte).

El nivel perlocutivo del discurso del fraile es, en esta escena, también evidente, «somatizado» en los personajes, desde los suspiros que apunta la didascalia hasta el desmayo de una mujer que pronto conocemos como Sabelita. Ésta puntualiza, en la escena siguiente, los efectos perlocutorios del discurso del fraile:

SABELITA. Fray Jerónimo me miraba desde el púlpito. ;Yo sentía aquellos ojos de brasa fijos en mi!... No puedo olvidar sus palabras. Estoy en pecado mortal y así me cogerá la muerte... Daban miedo los ojos de Fray Jerónimo... Sus palabras las tengo clavadas en el corazón, como tiene las espadas la Virgen Santísima de los Dolores (p. 54).

13 Catherine KERBRAT-ORECCHIONI distingue el valor ilocutivo «primitivo», el que predomina en el enunciado y el valor «derivado", cuya aprensión resulta más problemática (dependiendo de elementos contextuales implícitos), L'implicite, Paris: Armand Colin, 1986, p. 69. 
El efecto perlocutorio se traduce aquí a través de una metáfora, comparándose las palabras con «espadas» clavadas en el corazón. También ha entendido ella el nivel ilocutivo «derivado» del discurso del fraile, subrayando la imposibilidad de redimirse y de evolucionar: «Estoy en pecado mortal y así me cogerá la muerte» (p. 54). Sin embargo, estaba dispuesta a cumplir con la aparente invitación a arrepentirse, como lo indica la voz anónima en la iglesia: «querrá arrepentirse, tía Juliana». Pero es conducida fuera de la iglesia, excluida simbólicamente de la comunidad cristiana que es ante todo la iglesia.

Para acercarse al significado del enunciado, no basta con entender lo que se dice o lo que se hace diciendo, sino que a veces es tan o más importante conocer el contexto del enunciado. Aparte de los condicionantes extra-dialogales (espacio, tiempo, caracterización social, física, psicológica del personaje), el mensaje puede quedar alterado por otros factores.

\section{Lo no-dicho}

En este apartado trataré de todos aquellos condicionantes del enunciado que están relacionados con el discurso, formando una especie de contexto «peri-dialogal» ${ }^{14}$. Las leyes conversacionales condicionan a priori la producción y recepción del discurso teatral, mientras que los contenidos implícitos ${ }^{15}$ (presupuesto y sobreententido) están inscritos en la formulación del enunciado y se inducen de él.

\section{Las leyes conversacionales}

Son todos aquellos códigos presentes, de manera indirecta, en el intercambio cotidiano, que hacen posible la comunicación. Son a la vez universales y pueden variar según las áreas geográficas, culturales, sociales, etc. Siguiendo la teoría de Paul Grice, Anne Ubersfeld propone nombrar las cuatro categorías en las que se pueden dividir las «leyes conversacionales»: cantidad, cali-

14 Noción que corresponde a lo que CoSNIER y BRosSARD llaman «co-texto»: «... une partie du langage est non verbale et il est vrai qu'il y aussi du non verbal qui n'est pas du langage; c'est la distinction à faire, rarement faite, entre le non-verbal cotextuel, et le non verbal contextuel», en «Communication non verbale: Co-texte ou contexte?», La communication non verbale, Nauchâtel-Paris: Delachaux et Niestlé, 1984, p. 7.

15 Catherine KERBRAT-ORECCHIONI los designa bajo el término genérico de «inférence», que define así: «Nous appelerons «inférence» toute proposition que l'on peut extraire d'un énoncé, et déduire de son contenu littéral en combinant des informations de statut variable (internes ou externes)», (L'implicite, p. 24). 
dad, relación y modalidad ${ }^{16}$. En el teatro estas leyes se violan constantemente. Si esta violación es constante, es que el teatro es el lugar en que estas leyes se muestran, se ven y se oyen. Por ejemplo, la mentira en la vida no se entiende, o se entiende después, pero en el teatro el espectador sabe que el locutor miente. Éste es el caso de la última escena de Cara de Plata, en la que el Abad pide paso al Caballero para llevarle los últimos sacramentos al sacristán, que finge estar en trance de muerte. Aquí la estratagema de la mentira fracasa: Don Juan Manuel no se cree la agonía del sacristán y el lector/espectador sabe que se trata de una trampa. Por ello, se convierte el ritual religioso en una escena grotesca, estrafalaria, sacrílega, que finaliza la pintura de ese mundo decadente, sin valores.

El insulto, violación verbal del territorio personal, de la «faz positiva» del individuo ${ }^{17}$, es un recurso constante en las tres obras, característica del discurso de todos los miembros de la familia Montenegro. Me interesa aquí detenerme en un ejemplo específicamente violento, el de la escena de violación de Liberata por Don Pedrito. Escena aún más terrible cuando nos enteramos (más adelante) de que ésta es amante de Don Juan Manuel, de quien está preñada. Se trata de la cuarta escena de la segunda jornada de Águila de blasón:

Sobre verdes prados el molino de PeDro ReY. Delante de la puerta, una parra sostenida en poyos de piedra. Los juveniles pámpanos parecen adquirir nueva gracia en contraste con los brazos de la vid centenaria, y sobre aquellas piedras de una tosquedad céltica. Vuelan los gorriones en bandadas, y en lo alto de la higuera abre los brazos el espantajo grotesco de una vieja vestida de harapos, con la rueca en la cintura, y en la diestra, a guisa de huso, el cuerno de una cabra. Sentada a la sombra del emparrado está la molinera, fresca y encendida como las cerezas de santa María de Meis. LIBERATA LA BLANCA bate en un cuenco la nata de la leche, y en la rosa de los labios tiene la rosa de un cantar. Por el fondo de la era asoma un caballero cazador: Es el primogénito del Mayorazgo: Se llama DON PEDRITO.

LIBERATA. ;Vexo Cangas, vexo Vigo, tamen vexo Redondela!

16 Así los define en Lire le dialogue: la categoría de la cantidad concieme a la cantidad de informaciones proporcionadas en un contexto determinado por un enunciado, que no tiene que carecer de datos importantes ni tampoco exceder el número conveniente. La calidad se refiere a la relación del discurso con la verdad (no hay que afirmar lo que cree que es falso, lo que no sabe con certeza). Por relación, entiende la estudiosa la adecuación de la palabra al contexto de la conversación (hablar como conviene según los interlocutores). Por fin, la modalidad (hablar claro) es una categoría fundamental en el intercambio, en la medida en que es el condicionante mayor de la recepción del mensaje. A estas cuatro reglas básicas, se añaden otras reglas sociales, estéticas o morales, que los interlocutores suelen observar en la mayoría de los casos (la cortesía por ejemplo).

17 Así define Catherine KerBRAT-ORECCHIONI la teoría de las faces, enunciada por el sociólogo Goffman: la faz negativa es la necesidad para cada uno de defender el territorio de su yo, y la faz positiva es la necesidad de ser reconocido y apreciado por los demás (L'implicite, p. 229). 
ivexo a Ponte de San Payo,

camiño da miña tierra!

DON PEDRTTO. ;Buena vista tienes, zorra parda!

LIBERATA. iAsús!... A ustede no lo había visto.

DON PEDRTO. ¿Y el cabrón de tu marido?

LIBERATA. ¡QUé guisa de hablar para un caballero!

DON PEDRITO. Es cierto que está muy mal herido mi padre?

LIBERATA. Esa nueva trajo Don Galán.

DON PEDRITO. ¿Tú no lo has visto?

LIBERATA. No señor. Que me crea, que no, caí enferma en la cama con dolor de ijada.

DON PEDRITO. ¿Y Pedro Rey?

LIBERATA. Hoy ha ido a la villa por ver al amo.

DON PEDRITO. Necesito hablarle.

LIBERATA. Pues nunca mucho puede tardar.

DON PEDRTTO. Tenéis el molino casi de balde.

LIBERATA. ¿Qué dice, señor? ¿Ave María, de balde!

DON PEDRTO. De balde, porque doce ferrados de trigo y doce de maiz no son renta. ¡Y eso cuando la pagáis!

LIBERATA. Será porque el amo nos la perdona. ;Ave María, de balde un molino que la mitad del año solamente tiene agua para una piedra! ;Las otras dos es milagro que muelan pasado San Juan!

DON PEDRITO. Hoy me parece que muelen todas.

LIBERATA. Porque tenemos el agua de los riegos.

DON PEDRITO. Pues como la mitad del año solamente muela la piedra de maíz y no da más renta que pagáis, yo vengo a libraros de esa carga.

LIBERATA. ¿Qué dice el señor?

DON PEDRTTO. ;Eso!... Que dejéis por buenas el molino.

DON PEDRrTo se pone en pie, mira en torno y ríe con risa de lobo. La molinera, que siente miedo, también vuelve los ojos al camino y el camino está solitario. LIBERATA quiere levantarse y entrar en la casa.

DON PEDRITO. Vuelve a sentarte, Liberata la Blanca.

LIBERATA. Iba por unos higos para ofrecérselos. Los hemos cogido esta mañana y algo verdes están, pero los pardales no dejaban uno.

DON PEDRTOO. Buen maestro tienen en Pedro Rey.

LIBERATA. ¿Quiere que le ordeñe la vaca?

DON PEDRTO. Quiero que vuelvas a sentarte, zorra parda.

LIBERATA. No se enoje por eso.

DON PEDRTTO. Es preciso que me paguéis a mí la renta que mi padre no cobra, y si no podéis pagarla, que dejéis el molino.

LIBERATA. ¿Vino con licencia del amo?

DON PEDRTOO. Yo de nadie necesito licencia... O me pagáis a mí cien ferrados de maíz, que toda la vida rentó el molino, o mañana mismo lo dejáis al casero que antaño lo llevaba.

LIBERATA. ;Cómo se conoce que tiene dos hijas mozas el señor Juan de Vermo!

DON PEDRTTO. Pero para que se acuesten conmigo no se requiere que duerma debajo de la cama ningún cabrón.

LIBERATA. iSi lo dice por mí, sepa que tengo mucha honradez, y que sólo mi marido me calienta las piernas en la cama! iMás honradez que las hijas del de Vermo!

DON PEDRITO. Voy a meterte en el podrido bandullo un puñado de munición lobera (p. 78-80).

Asistimos a la irrupción de Don Pedrito en el cuadro bucólico del molino pintado por la larga didascalia intermedia. El momento de tranquilidad y de 
placer (simbolizado por el vuelo de los gorriones, la canción folclórica de la molinera que bate la nata de la leche) contrasta violentamente con el insulto, «zorra parda», a modo de saludo. La ubicación, al principio del intercambio, en el consagrado sitio de las fórmulas rituales de apertura, constituye una violación lingüística que anticipa lingüísticamente la violación final, descrita en un largo párrafo didascálico.

La violación de esa ley de cortesía no deja de sorprender a Liberata, quien reaccionará con sutileza. Después de oír el segundo insulto (relativo ahora al marido «cabrón»), le recuerda su estatuto social de Mayorazgo, subrayando su doble falta:

- como ser humano (no se puede tratar a una persona como se está portando con ella)

- y como señor perteneciente a una clase social superior.

Pero a esta doble violación, corresponde otra violación implícita en la elección del insulto (zorra) y explícita en la palabra «cabrón». Don Pedrito viola aquí también la regla social de ocultación del derecho de pernada. Constitutivo del funcionamiento social de la Galicia pintada por ValleInclán, el derecho de pernada es algo que se esconde, indecible, convención trastornada aquí por Don Pedrito. Incluso Liberata no la va a reconocer, violando también la ley de sinceridad para el mayor regocijo del espectador (afirma al final: «Sepa que tengo mucha honradez»).

La violencia del primogénito para con Liberata se justifica por la oposición al padre y la necesidad de imponerse frente a él, como lo atestigua la réplica «yo de nadie necesito licencia». Esta voluntad de afirmarse se va a concretar en la reivindicación de los privilegios económicos de la renta por el molino, símbolo del poder paterno. Y como el tema de la renta va relacionado con el derecho de pernada (tanto por parte del padre como del hijo, que reproduce el mismo esquema con la familia de Vermo), Liberata es la víctima ideal, como molinera y amante, de Don Pedrito. La violación física es otra forma de amenazar el poder (la potencia sexual) del padre, amenaza que corre pareja con las órdenes de Don Pedrito. Con sutileza, intenta Liberata ganar tiempo, con estratagemas que le podrían obligar a alejarse de su atacante, cada vez más peligroso, «con risa de lobo». Esta tensión desemboca en el terrible acto de violencia verbal, que anuncia, con la fuerza de la metáfora animal, la barbarie del asalto sexual final.

\section{Lo presupuesto}

Así lo define C. Kerbrat-Orecchioni: 
Nous considérons comme présupposées toutes les informations qui sans être ouvertement posées (i.e., sans constituer en principe le véritable objet du message à transmettre) sont cependant automatiquement entraînées par la formulation de l'énoncé dans lequel elles se trouvent intrinsèquement inscrites, quelque soit la spécificité du cadre énonciatif ${ }^{18}$.

Y recuerda, para ilustrar su definición, el famoso ejemplo de Ducrot 19 «Pierre a cessé de fumer». Cuando digo Pedro ha dejado de fumar, el presupuesto es que existe Pedro y que este Pedro fumaba. El enunciado puede ser negado, sometido a una interrogación, a una variación, pero el presupuesto no se toca.

En el teatro, lo presupuesto forma parte de las condiciones de enunciación: hay varios presupuestos, de orden factual, lógico, ideológico.

Por ejemplo, en Cara de Plata, el intercambio dialogal entre el Viejo de Cures y Cara de Plata está condicionado por varios presupuestos factuales e ideológicos:

1. hubo un pleito acerca del derecho de paso

2. ganó el caballero

3. estamos todavía en un sistema arcaico de Mayorazgo, con centralización de poderes

4. Cara de Plata es el hijo predilecto del Caballero, de verdadera sangre azul:

EL VIEJO DE CURES. ¡Galán vinculero! ¿Es verdad que al presente está privado el tránsito?

CARA DE PLATA. Es verdad.

EL VIEJO DE CURES. ¿Y hemos de llevar el ganado por la vuelta del río, y pasar la barca, al ir y al volver de esta gran feria de Viana?

CARA DE PLATA. Así es la sentencia.

EL VIEJO DE CURES. A duras leyes, jueces clementes, dice el saber de los antiguos.

CARA DE PLATA. Mi padre se cansó de ser clemente.

EL VIEJO DE CURES. ;A lo menos fuéranos permitido el tránsito para estas ferias anuales del Corpus! iA lo menos fuéranos eso concedido, que según luces de curiales, es lo que vinieron gozando los pasados!

EL VIEJO DE CURES. Eso os daba mi padre, y fuisteis al pleito.

EL VIEJO DE CURES. Los de Cures no fuimos. En ese referente está engañado el señor Mayorazgo. Yo soy el árbol de más años. Contando los hijos y nietos casados, suben de treinta las puertas donde puede morar Quinto Pío. iAsi es! Y por más señalado, Quinto de Cures. Cristiano viejo, aun cuando en los días presentes, no se reconoce diferencia entre nuevos y viejos. ;Así es! Hoy no queda por esa tie-

18 L'implicite, p. 25

19 Oswald DuCroT, «Note sur la présupposition et le sens littéral», postaface à Paul Henry, Le mauvais outil. Langue, sujet et discours, Paris: Klincksieck, 1977, p. 173. 
rra otro judío, que el inglés de los Evangelios. Pues era aquel decir, que no pleiteamos los de Cures.

CARA DE PLATA. Pero fuisteis de testigos falsos.

CLAMOR DE LOS VAQUEROS. iEstá mal informado! „No somos de esa condición! ¿Le inclinaron en contra las orejas!

EL VIEJO DE CURES. ¡Sangre de Montenegro, el tránsito a todos nunca podrá quitarse! Es la costumbre del tiempo de los viejos, y las costumbres hacen la ley. Los de Cures no seremos rebeldes, y de hoy caminaremos por la vuelta. ¡Así es! Pero aquel jinete que viene trotando, no quedará sin paso. El mismo rey, ante otros reyes baja la espada.

CARA DE PLATA. Viejo de Cures, si no pasan los que caminan a pie, no pasarán los que vienen a caballo.

EL VIEJO DE CURES. ¡Asi cumplía!

CARA DE PLATA. Y así es la doctrina de mi padre.

EL VIEJO DE CURES. ¡Amén! Nieves paternas para el hijo espejos. jAsi es! Y grillos de bronce sus mandamientos (p. 63-64).

Presenciamos una curiosa segunda exposición que da los mismos elementos informativos que en la primera escena. Vuelve a aludir el Viejo de Cures al problema del derecho de paso, que es un derecho de «costumbre». Vuelve a recordar que el caballero ganó el pleito. ¿Por qué? ¿De qué sirve esta nueva exposición?

El viejo de Cures, en su afán de encontrar una solución diplomática, va a intentar cambiar las reglas del juego y los presupuestos ideológicos y factuales antes mencionados. Solicitando al hijo predilecto del padre (el mejor intercesor potencial), intenta quebrar el poder omnipersonal del Mayorazgo para encontrar una solución al problema del derecho de paso.

Con el apóstrofe «galán vinculero» y las primeras interrogaciones, el Viejo intenta romper con el presupuesto factual de la victoria ya sabida del caballero. Con el adjetivo «vinculero», le confiere a Cara de Plata el mismo poder que a su padre (aunque no sea el primogénito). Le da pues la oportunidad de cambiar las leyes, de decidir y de oponerse al padre como representante de la nueva generación, más comprensible, más humana, «A duras leyes, jueces clementes». Intenta modificar los presupuestos:

1. estamos en un sistema de Mayorazgo pero el Caballero tiene descendencia;

2. hubo un pleito pero puede haber un nuevo acuerdo, más allá de las leyes;

3. ganó el caballero pero Cara de Plata puede no seguir la sentencia;

4. Cara de Plata tiene sangre azul pero no es tan arcaico como su padre.

Pero la figura del padre es omnipresente en el discurso de Cara de Plata. Nunca habla en nombre propio, siempre pronuncia frases impersonales, se refiere dos veces explícitamente a su padre. Cara de Plata desaparece bajo 
el poder paterno: el «Señor Mayorazgo». Cara de Plata tiene la misma posición ideológica, de apoyo al padre y al señor, todopoderoso. Cuando se da cuenta de la imposibilidad de convencer a Cara de Plata, el Viejo intenta otra argumentación, fundada en el presupuesto ideológico de la permanencia y de la tradición. Por eso, cambia la fórmula de apóstrofe a Cara de Plata, llamándole «Sangre de Montenegro», que remite a la nobleza familiar y sus consiguientes derechos respecto a sus súbditos. Pero al final, reconoce el Viejo la imposibilidad de cambiar los presupuestos, siendo Cara de Plata el doble de su padre: «Nieves paternas para el hijo espejos».

\section{Lo sobreentendido}

Mientras que el presupuesto está impuesto por el enunciado, formando parte de él, el sobreentendido depende de las condiciones de enunciación y de la capacidad de cada interlocutor de conectar con el contenido implícito ${ }^{20}$. En el teatro, resulta más difícil de entender, a no ser que las didascalias de acción verbal aclaren el contexto implícito del diálogo. La escenificación resolverá, por fuerza, el problema de la multiplicidad de los sobreententidos posibles, eligiendo un modo de enunciación o de actuación que dejen entender o ver lo no dicho.

Anne Ubersfeld recoge, una vez más, el ejemplo cotidiano del «dejar de fumar»: mi hermano ya no fuma. Los dos presupuestos implicados por el enunciado son: 1 . tengo un hermano: 2 . fumaba. Lo que dice es que ahora ya no fuma, pero tal enunciado supone un sinfín de sobreentendidos posibles. Por ejemplo: se lo prohibió el médico; tuvo una crisis de asma; teme al cáncer; su mujer le deja (es tirano o es prudente); los cigarrillos cuestan demasiado. Los sobreentedidos son inagotables, según la índole de los receptores, su relación con el locutor.

En la escena de Cara de Plata en que doña Jeromita viene a buscar a SABELITA, después del enfrentamiento con el Abad, podemos analizar el triloquio entre el Caballero, Jeromita y Sabelita, a partir del juego con los distintos sobreentendidos de los enunciados de los personajes:

20 Recurriré una vez más a la definición de Catherine KERBRAT-ORECCHIONI, «La classe des sous-entendus englobe toutes les informations qui sont susceptibles d'être véhiculées par un énoncé donné, mais dont l'actualisation reste tributaire de certaines particularités du contexte énonciatif...; valeurs instables, fluctuantes, neutralisables, dont le décryptage implique un «calcul interprétatif» toujours plus ou moins sujet à caution, et qui ne s'actualisent vraiment que dans des circonstances déterminées... Valeurs qui sont toutefois pour nous véritablement inscrites dans l'énoncé...» (L'implicite, p. 39). 
DOÑA JEROMITA. ¡Qué genio fantástico!

EL CABALLERo. ¿Cómo queda mi amigo el clérigo?

DOÑA JEROMITA. Con arrebato de sangre, pienso que lo sabe.

EL CABALLERo. Siempre ha sido en la mesa un templario.

DOÑA JEROMITA. ¡Jesús, mil veces! Otra causa motiva su achaque, y es el oprobio que le hizo un vástago de esta casa.

EL CABALLERO. Ya conozco ese pleito.

DONA JEROMTAA. ¿Y cómo lo sentencia?

EL CABALLERO. iNo puedo romper la vara de juez que me ha puesto en la mano el Diablo.

DOÑA JEROMTTA. ¡Jesús, mil veces!

EL CABALLRO. No puedo dar ese mal ejemplo en mi casa.

DOÑA JEROMITA. Y da otros peores.

EL CABALLERo. ¡Conforme! Pero éste no puedo darlo.

DOÑA JEROMTTA. ¡Jesús, mil veces! ¿Quiere decirse que sostiene la herejía de su rapaz?

EL CABALLERo. Estoy obligado.

DONA JEROMITA. ¿Sabe bien lo que hizo?

EL CABALLERO. Y lo lamento.

DONAA JEROMTrA. Entonces, ¿por qué lo sostiene, y rompe así las amistades?

El CABALLERo. ;Yo no las rompo! Pero tengo que llevar recta mi vara.

DOÑA JEROMTTA. Tarde o temprano habrá de doblarla.

EL CABALIERO. No lo esperes. Conozco el propósito que traes. Sé a lo que vienes.

DOÑA JEROMITA. ¿Y que dice?

EL CABALLERO. ¿Nada!

DOÑA JEROMITA. ¡No extrañará que le reclame la oveja de mi corte!

EL CABALLERO. No lo extraño.

DOÑA JEROMITA. Puestas en discordia las familias, hasta por miramiento me cumple reclamar la sobrina. ¿No lo estima de esa conformidad?

EL CABALLERO. ¡Un rayo te parta!

DONA JEROMITA. ¡Jesús, mil veces!

SABELITA. jAdios, piedras de Lantañón!

DOÑA JEROMITA. ¡Seca prontamente esas lágrimas!

EL CABALLERo. No llores, niña. Tú volverás, que el tiempo es mudanza.

DOÑA JEROMITA. Y muerte también.

EL CABALLERO. También.

DOÑA JEROMTRA. Y castigo.

EL CABALLERO. ;Acaso! Acércate, ahijada.

DOÑA JEROMITA. Bésale la mano a tu padrino, y vamos caminando.

EL CABALLERo. iNo llores, niña! Comprende que no puedo torcer mi vara.

SABELTTA. No la tuerza. ¡Adiós, para siempre, padrino!

EL CABALLERo. Para siempre, no. Tú volverás.

SABELTTA. iQuién sabe!

EL CABALLERO. Si Dios no lo quiere, lo querrá el diablo (p. 76-77).

El presupuesto en el que se funda el intercambio queda definido al principio del fragmento, cuando dice el Caballero: «no puedo romper la vara de juez que me ha puesto el diablo». Lo que es innegable es que el diablo ha dado al Caballero una vara de juez, lo que viene a significar que Don Juan es un juez diabólico, con justicia diabólica. Lo que afirma aquí Don Juan Manuel es la imposibilidad de no cumplir con su misión diabólica, con varios sobreentendidos posibles: 
1. no puedo, porque no quiero, porque hago lo que me da la gana, soy el juez en mi casa;

2. no puedo porque mi hijo es otro yo, es el único que tiene sangre azul, le tengo que apoyar;

3. no puedo porque no soy capaz, no estoy libre, estoy bajo el poder del diablo, estoy dominado, tengo un contrato con el diablo.

Estos tres sobreententidos corresponden al desarrollo siguiente:

1. no puedo dar ese mal ejemplo en mi casa, soy yo quien decido el bien y el mal, hago justicia;

2. estoy obligado y lo lamento pero la filiación es un deber moral, ética familiar de la sangre, superior a cualquier juicio de valor;

3. «tengo que»: contrato diabólico, deber relacionado a este contrato, superior a los demás.

Volvemos a encontrar el mismo juego de sobreentendidos, cuando Doña Jeromita, siguiendo con la misma metáfora que el caballero, afirma: «Tarde o temprano habrá de doblarla». Lo que sugiere es: me voy a vengar/tengo un elemento de chantaje/sé que quiere a Sabelita/usted cederá tarde o temprano.

El caballero niega rotundamente este sinfín de posibilidades, subrayando que ha entendido los sobreentendidos de Doña Jeromita. Pero nunca los enuncia, conformándose con decir: «conozco el propósito que traes», «sé a lo que vienes», para el mayor regocijo del espectador. Cuanto más que Doña Jeromita le pide una contestación sin que se hayan aclarado los sobreentendidos: « $i Y$ que dice». Hacen falta cuatro réplicas en stychomitia para que el chantaje se exponga claramente: «¿No le extrañará que le reclame la oveja de mi corte?» Pero tampoco doblará su vara el Caballero, fracasando la tentativa de chantaje. El Caballero, en esta primera comedia, es todavía omnipotente, afirma su poder sobre todo y todos, a pesar de cualquier circunstancia.

Al final de este estudio, incompleto y ciertamente esquemático, podemos sugerir que el diálogo teatral de Las comedias bárbaras no es, ni mucho menos, innovador o vanguardista. Inscrito en unas formas dialógicas tradicionales, predeterminado por unos referentes históricos, culturales y míticos identificables, no trastorna las reglas básicas del intercambio dialogal, creando un efecto de «verosimilitud», de «mímesis». No anticipa, en estas tres obras, ningún procedimiento característico de la escritura teatral contemporánea, la fragmentación, la descontextualización, la desaparición del personaje, la desemantización del discurso ${ }^{21}$, características de la dramaturgia de $E l$ público

21 Véase Eric Eigenmann, La parole empruntée: Sarraute, Pinget, Vinaver: théâtre du dialogisme, Paris: L'Arche, 1996. 
de García Lorca. Volvemos pues a nuestra afirmación inicial: el carácter vanguardista de la trilogía de Valle-Inclán estriba en la escritura didascálica, que confiere una importancia dramatúrgica fundamental a otros sistemas de signos (anticipando la concepción polisémica que la escena moderna explotará hasta sus últimos recursos, junto con la literatura dramática ${ }^{22}$ ). Más allá de una dramaturgia textual que privilegia la imagen, construyendo cuadros escénicos precisos y complejos, Las comedias bárbaras prefiguran también la hipertrofia del texto didascálico, y las variaciones enunciativas, que convierten esa parte «marginal» del texto teatral en una verdadera creacción verbal.

22 Con obras exclusivamente didascálicas, véase el texto de Rodrigo GaRCía, Mi cuerpo llora, no hay palabras, en Corps en scène, Carnières: Lansman, 2001. 